\title{
Expanding the Universe of Universal Coverage: The Population Health Argument for Increasing Coverage for Immigrants
}

\author{
Arijit Nandi · Sana Loue - Sandro Galea
}

(C) Springer Science+Business Media, LLC 2009

\begin{abstract}
As the US recession deepens, furthering the debate about healthcare reform is now even more important than ever. Few plans aimed at facilitating universal coverage make any mention of increasing access for uninsured non-citizens living in the US, many of whom are legally restricted from certain types of coverage. We conducted a critical review of the public health literature concerning the health status and access to health services among immigrant populations in the US. Using examples from infectious and chronic disease epidemiology, we argue that access to health services is at the intersection of the health of uninsured immigrants and the general population and that extending access to healthcare to all residents of the US, including undocumented immigrants, is beneficial from a population health perspective. Furthermore, from a
\end{abstract}

\section{A. Nandi}

Center for Population and Development Studies,

Harvard School of Public Health, Boston, MA, USA

S. Loue

Department of Epidemiology and Biostatistics,

School of Medicine, Case Western Reserve University,

Cleveland, $\mathrm{OH}$, USA

S. Galea $(\bowtie)$

Department of Epidemiology, Center for Global Health, Institute for Social Research, University of Michigan School of Public Health, 109 Observatory, Room 3663,

Ann Arbor 48109, MI, USA

e-mail: sgalea@umich.edu

S. Galea

Department of Epidemiology, Columbia University Mailman School of Public Health, New York, NY, USA

S. Galea

Survey Research Center, Institute for Social Research,

Ann Arbor, MI, USA health economics perspective, increasing access to care for immigrant populations may actually reduce net costs by increasing primary prevention and reducing the emphasis on emergency care for preventable conditions. It is unlikely that proposals for universal coverage will accomplish their objectives of improving population health and reducing social disparities in health if they do not address the substantial proportion of uninsured non-citizens living in the US.

Keywords Immigrant · Undocumented · Non-citizen · Access to services · Health insurance $\cdot$ Reform · Epidemiology

\section{Introduction}

President Obama has said repeatedly that healthcare reform is one of his top priorities. Prominent democrats, including Hillary Clinton, have long called for providing universal access to healthcare coverage and it is likely that Congress will debate how best to accomplish this in the coming months. As the US recession persists, the imperative for healthcare reform grows. According to the Bureau of Labor Statistics, the unemployment rate reached a sixteen-year high in December of 2008 [1]. In that month, there were more than eleven million unemployed in the US, an increase of more than three and-a-half million since the start of the recession 1 year earlier. As firms falter and fail, workers lose their jobs, and along with them, their health insurance. This will likely increase the number of uninsured in the US. Concurrently, as tax revenues fall, governments at all levels are likely to scale back on social and other salutary resources at a time when they are needed most. This trend, along with the ongoing retirement of the 
baby-boomers, portends an increasing burden on our healthcare system in the years to come. Therefore, furthering the debate about healthcare reform is now even more important than ever.

All of the healthcare reform plans proposed during the presidential campaign, although distinct in their means, had one end in common - to reduce the number of uninsured. Taking this one step further, recent Democratic candidates, including Hillary Clinton and Barack Obama, proposed accessible health care coverage for all. A productive discourse about how to achieve universal coverage should start with defining the target population. The most frequently cited estimate provided by the different campaigns, including the Obama campaign [2], was that were are approximately 45 million uninsured Americans lacking health insurance. This number is derived from the Current Population Survey (CPS), a monthly survey conducted by the US Census Bureau that is representative of the US civilian noninstitutionalized population [3]. The sampling frame for the survey includes all individuals who indicate that the US is their usual place of residence, including citizens, foreignborn lawful permanent residents, temporary immigrants, humanitarian immigrants, and undocumented immigrants. Consequently, the frequently cited 45 million uninsured Americans is actually an estimate for the number of uninsured individuals living in America, not the number of uninsured citizens. Therefore, healthcare reform proposals aimed at providing universal coverage by reducing the reported 45 million Americans without it have misspecified the universe of the uninsured. This is an important distinction that needs to enter the debate on healthcare reform.

Most explanations for the substantial proportion of individuals lacking health insurance in the US take a health economics perspective and center around pricing issues. While these considerations are certainly important, one barrier that is rarely mentioned in the discourse is legal status. Although the CPS does not specifically ask about the legal status of its respondents, estimates suggest that approximately 10 of the 45 million uninsured individuals living in the US are foreign-born non-citizens [3], many of whom are likely undocumented immigrants. Few plans aimed at facilitating universal coverage, including the one delineated by President Obama during his campaign, make any mention of increasing access for non-citizens who are legally restricted from coverage; this includes legal immigrants who have been in the US for less than 5 years and are denied Medicaid and State Children's Health Insurance Program (SCHIP) coverage, as well as undocumented immigrants. As far as we know, only one proposal, the recent Call to Action Health Reform 2009 plan by Senator Max Baucus [4], attempts to reduce the 10 million uninsured foreign-born non-citizens living in the US by eliminating the five-year waiting period before legal residents are eligible for
Medicaid and SCHIP. Although some would argue that universal coverage implies access for citizens only, we suggest that coverage for all members of our society, including citizens, legal residents, and undocumented immigrants, is important and should be considered.

Given the privatized employer-centric nature of the US healthcare system, along with a dismal history of extending coverage to even the most vulnerable of groups (e.g., President Bush's veto of SCHIP in 2007), few arguments have been made for extending healthcare to immigrant groups. Those that have commonly take a human rights approach [5]. While we believe that health, and specifically access to healthcare, is a human right, this belief is not universally held and has failed to gain political traction. After all, it was only a few months ago that John McCain categorized access to healthcare as a responsibility rather than a right [6]. Recognizing the limitations of this perspective, we conducted a critical review of the peerreviewed, public health literature covering topics related to the health status and access to health services among immigrant populations in the US. Based on the results of this review, and specifically examples from infectious and chronic disease epidemiology, we argue that access to health services is at the intersection of the health of uninsured immigrants and the general population and that extending access to healthcare to all residents of the US, including undocumented immigrants, is beneficial from a population health perspective.

\section{Methods}

We critically reviewed the peer-reviewed public health literature concerning the health status and access to health services among immigrant populations in the United States. We searched the Index Medicus and ISI Web of Knowledge databases for combinations of the following keywords: 'access', 'health services', 'insurance', 'health', 'health status', immigrant', 'undocumented', 'legal status', 'expenditures'. This search identified a broad literature spanning several hundred articles. From these articles, as well as their references, we selected papers that provided empirical data from which to draw inference about the potential health and financial impacts of increased access to health services among immigrant populations. As such, the review methodology was designed to inform a commentary review rather than a systematic review.

\section{Results and Commentary}

Herd immunity suggests that the level of access to basic prevention and treatment services among immigrants and 
their children influences the likelihood of epidemic spread among the general population by conditioning the probability that susceptible individuals interact with infected individuals. For example, limited access to basic preventative measures among undocumented immigrants, such as immunizations [7], may increase the proportion of individuals susceptible to a particular disease in the population. Additionally, restricted access to testing may increase the proportion of infected individuals in the population by increasing the probability that persons unaware that they are infected come into contact with susceptible individuals [8]. This mechanism may partly explain the recent increase in HIV/AIDS prevalence both among Mexican migrants and the rural communities that are most likely to export them $[9,10]$. Other work shows that restricted access to prenatal care among undocumented immigrants may contribute to increased morbidity due to sexually transmitted infections [11]. Undocumented immigrants may also have a relatively higher burden of preexisting disease, including tuberculosis [12], and wait longer before seeking medical care [13], which increases the risk of transmission. Restricting access to basic treatments among undocumented immigrants may increase the proportion of individuals living in the US who are infected with a particular disease and, in turn, increase the probability of disease transmission within the general population. Together, this evidence suggests that factors that influence the level of access to basic health services among immigrants may directly impact the burden of infectious disease in the general population.

From a population health perspective, it is also important to consider the access to and use of health services among the children of immigrants. Both undocumented children and US-born children of undocumented immigrant parents use health services at a lower frequency than children of non-immigrant parents [14]; for example, a recent study found that the odds of timely immunization series completion were 14 percent lower for children of immigrants compared to non-immigrants and that children of non-citizen mothers who have lived in the US for less than 5 years were the least likely to complete their immunization series on time [15]. Given that the children of immigrants are more likely to randomly mix within the general population than their parents, they may represent an important pathway linking the health of immigrants and the health of the general population. This potential for widespread outbreaks was exemplified by an epidemic of drug-resistant tuberculosis that spread from an immigrant teenager to almost one-quarter of the California high school's student population [16].

The degree to which undocumented immigrants access health services may also indirectly affect the health of the general population. Immigrants, particularly undocumented immigrants, are more likely to obtain health services from clinics and emergency rooms than a primary care physician compared to non-immigrants [17]. This is reflected by health care expenditures. Although overall per capita health spending for immigrants, including uninsured immigrants, is disproportionately low, expenditures on emergency medical services are disproportionately high compared to those for non-immigrants [18]. The emphasis on emergency services over primary care among undocumented immigrants contributes to an increased prevalence of complications from chronic diseases including diabetes and asthma that, along with their associated costs, could be prevented [19, 20]. For example, a study of undocumented immigrants with end-stage renal disease (ESRD) found that those who were treated with only emergent dialysis utilized emergency room facilities more frequently than undocumented immigrants who were treated at the same standard provided to US citizens; consequently, hospital costs were almost four times higher for undocumented immigrants with restricted care for ESRD [21]. With research suggesting that a large proportion of morbidity and related health care expenditures among undocumented immigrants could be avoided through adequate access to primary care [20], restricting access to health services among immigrant populations may actually be more expensive than offering the standard of care provided to non-immigrants.

\section{Conclusions}

It is unlikely that proposals for universal coverage will accomplish their objectives of improving population health and reducing social disparities in health if they do not correctly specify the universe of the uninsured. Without an understanding that almost one-quarter of uninsured individuals living in America are non-citizens, many of whom are legally restricted from certain types of coverage, no plan will be truly universal. Although universality may not be the objective of healthcare reform proposals that implicitly aim to extend access only to citizens, extant infectious and chronic disease epidemiologic research suggests that excluding large proportions of the population from adequate coverage has a negative impact on not only the uninsured, but also on the general population. Furthermore, from a health economics perspective, increasing access to care for immigrant populations may help to reduce net costs by increasing primary prevention and reducing the emphasis on emergency care for preventable conditions.

Acknowledgments This research was supported in part by grants from the National Institutes of Health (DA 017642 and MH 078152). 


\section{References}

1. Bureau of Labor Statistics. The employment situation: January 2009. http://www.bls.gov/news.release/archives/empsit_020620 09.pdf/. Accessed 15 April 2009.

2. Obama B, Biden J. Barack Obama and Joe Biden's plan to lower health care costs and ensure affordable, accessible health coverage for all organizing for America. 2008. http://www.barack obama.com/issues/healthcare/. Accessed 26 Jan 2009.

3. DeNavas-Walt C, Proctor BD, Smith JC. Bureau USC: Current population reports, P60-235, income, poverty, and health insurance coverage in the United States: 2007. Washington, DC: U.S. Government Printing Office; 2008.

4. Baucus M. Call to action health reform 2009. Senate Committee on Finance. 2008. http://finance.senate.gov/healthreform2009/ home.html. Accessed 26 Jan 2009.

5. Cole P. Migration and the human right to health. Camb Q Healthc Ethics. 2009;18(1):70-7.

6. CNN. Transcript of second McCain, Obama debate. http://www. cnn.com/2008/POLITICS/10/07/presidential.debate.transcript/. Accessed 26 Jan 2008.

7. Blaney S, Coady MH, Galea S, Ompad DC, Glidden K, Sisco S, Vlahov D. Determinants of influenza vaccination among undocumented immigrant populations in underserved areas of New York City. In: American Public Health Association Annual Meeting. Washington, DC. 2007.

8. Marks G, Crepaz N, Janssen RS. Estimating sexual transmission of HIV from persons aware and unaware that they are infected with the virus in the USA. AIDS. 2006;20(10):1447-50.

9. Hirsch JS, Meneses S, Thompson B, Negroni M, Pelcastre B, del Rio C. The inevitability of infidelity: sexual reputation, social geographies, and marital HIV risk in rural Mexico. Am J Public Health. 2007;97(6):986-96.

10. Sanchez MA, Lemp GF, Magis-Rodriguez C, Bravo-Garcia E, Carter S, Ruiz JD. The epidemiology of HIV among Mexican migrants and recent immigrants in California and Mexico. J Acquir Immune Defic Syndr. 2004;37(Suppl 4):S204-14.
11. Kuiper H, Richwald GA, Rotblatt H, Asch S. The communicable disease impact of eliminating publicly funded prenatal care for undocumented immigrants. Matern Child Health J. 1999;3(1): $39-52$.

12. Taylor Z, Nolan CM, Blumberg HM. Controlling tuberculosis in the United States recommendations from the American Thoracic Society, CDC, and the Infectious Diseases Society of America. MMWR Recomm Rep. 2005;54(RR-12):1-81.

13. Achkar JM, Sherpa T, Cohen HW, Holzman RS. Differences in clinical presentation among persons with pulmonary tuberculosis: a comparison of documented and undocumented foreign-born versus US-born persons. Clin Infect Dis. 2008;47(10):1277-83.

14. Huang ZJ, Yu SM, Ledsky R. Health status and health service access and use among children in U.S. immigrant families. Am J Public Health. 2006;96(4):634-40.

15. Buelow VH, Van Hook J. Timely immunization series completion among children of immigrants. J Immigr Minor Health. 2008; 10(1):37-44.

16. The New York Times. California school becomes notorious for epidemic of TB. New York: The New York Times; 1994.

17. Durden TE. Usual source of health care among Hispanic children: the implications of immigration. Med Care. 2007;45(8):753-60.

18. Mohanty SA, Woolhandler S, Himmelstein DU, Pati S, Carrasquillo $\mathrm{O}$, Bor DH. Health care expenditures of immigrants in the United States: a nationally representative analysis. Am J Public Health. 2005;95(8):1431-8.

19. American Diabetes Association. Economic costs of diabetes in the U.S in 2007. Diabetes Care. 2008;31(3):596-615.

20. DuBard CA, Massing MW. Trends in emergency Medicaid expenditures for recent and undocumented immigrants. JAMA. 2007;297(10):1085-92.

21. Sheikh-Hamad D, Paiuk E, Wright AJ, Kleinmann C, Khosla U, Shandera WX. Care for immigrants with end-stage renal disease in Houston: a comparison of two practices. Tex Med. 2007;103 (4):54-8, 53 . 